\title{
ANÁLISE LEGAL DA FLEXIBILIZAÇÃO DO CONTROLE DE JORNADA DE TRABALHO COM VISTAS AO PRINCÍPIO PROTETIVO DO TRABALHADOR.
}

\author{
LEGAL ANALYSIS OF THE FLEXIBILIZATION OF WORKDAY CONTROL \\ WITH VIEWS OF WORKER'S PROTECTIVE PRINCIPLE.
}

\author{
Tales Almeida Andrade ${ }^{1}$ \\ Leandro Alves Coelho ${ }^{2}$
}

\begin{abstract}
Resumo: O presente trabalho buscou analisar as alterações legislativas relativas ao Controle de Jornada de Trabalho emanadas da Lei n ${ }^{\circ}$ 13.874, de 20 de setembro de 2019 (Lei de Liberdade Econômica) à luz dos Princípios Protetivos do Trabalhador. O estudo esteve voltado ainda para contextualizar acerca do Controle de Jornada no Direito do Trabalho e a sua importância na Saúde e Segurança do Trabalho, bem como para expor os motivos que levaram a criação da Lei de Liberdade Econômica (Lei ${ }^{\circ}$ 13.874/2019). De oportuno, o presente trabalho apresentou os Princípios Protetivos do Trabalhador, assim como verificou as alterações legislativas e impactos promovidos pela Lei $n^{\circ}$ 13.874/2019 (Lei de Liberdade Econômica) no Controle de Jornada de Trabalho à luz da principiologia protetiva. Para tanto, o presente artigo conta com um estudo documental, abordagem qualitativa, bem como a revisão de literatura e o método dialético, a partir das ideias e posicionamentos doutrinários juslaboralistas. Por derradeiro, este trabalho acadêmico evidenciou um caráter multifacetado do Controle de Jornada, o qual apresenta um enfoque biológico, social e econômico; como também, demonstrou o insucesso dos objetivos principais da Lei de Liberdade Econômico e os elementos justificadores da inconstitucionalidade material desta.
\end{abstract}

Palavras-chave: Liberdade Econômica. Jornada de Trabalho. Proteção ao Trabalhador. Legislação.

\begin{abstract}
This paper sought to analyze the legislative changes related to the Control of Word Hours arising from Law No. 13.874, of September 20, 2019 (Economic Freedom Law) considering the Worker's Protective Principles. The study was also aimed at contextualizing the Control of Work Hours in Labor Law and its importance in Health and Safety at Work, as well as to expose the reasons that led to the creation of the Economic Freedom Law (Law No. 13.874/2019). In due course, this work presented the Worker's Protective Principles, as well as verified the legislative changes and impacts promoted by Law No. 13.874/2019 (Economic Freedom Law) in the Control of Work Hours considering the protective principle. Therefore, this article has a documental study, a qualitative approach, as well as a literature review and the dialectical method, based on ideas and doctrinal legal positions. Finally, this academic work evidenced the multifaceted character of Journey Control, which presents a biological, social, and economic focus; as well as it demonstrated the failure of the main objectives of the Economic Freedom Law and the justifying elements of its material unconstitutionality.
\end{abstract}

Keywords: Economic freedom. Workday. Worker Protection. Legislation.

\footnotetext{
${ }^{1}$ Advogado. Especialista em Direito Material e Processual do Trabalho pela Universidade Cândido Mendes (UCAN - Rio de Janeiro/RJ, Brasil), Mestrando em Economia Regional e Políticas Públicas da Universidade Estadual de Santa Cruz (UESC - Ilhéus/BA, Brasil), tales@almeidakorontai.com.br.

2 Advogado. Professor de Direito Material e Processual Tributário do Centro de Ensino Superior de Ilhéus/Faculdade de Ilhéus (CESUPI - Ilhéus/BA, Brasil). Mestre em Planejamento e Gestão Ambiental com ênfase em Tributação e Meio Ambiente pela Universidade Católica do Salvador (UCSAL - Salvador/BA, Brasil). Especialista em Metodologia do Ensino Superior com ênfase em Direito Tributário pela Universidade do Sul de Santa Catarina (UNISUL - Tubarão/SC, Brasil), leocoelhoadv@gmail.com.
} 


\section{INTRODUÇÃO}

O Direito do Trabalho se faz indispensável para estabelecer normas que recaem sobre as relações sociais, em especial, aquelas envolvendo vínculo empregatício, no qual um indivíduo (empregado) presta serviços em benefício de outrem (empregador), seja no interior das dependências deste ou de forma externa (Home office, Teletrabalho ou outra forma de trabalho à distância), em troca de uma contrapartida pecuniária.

Dentro desta linha de raciocínio, pode-se afirmar que a razão fática da seara juslaboral é a relação de trabalho subordinada, onde se verifica em um dos polos o obreiro hipossuficiente. Desse modo, a partir da despertada necessidade de regular a relação empregado-empregador percebida pela classe operária e a intervenção da figura no Estado nesta problemática social surge o Direito do Trabalho como conhecemos.

Todavia, considerando que os trabalhadores e empregadores têm interesses opostos na relação de trabalho, o regramento jurídico e mostra indispensável na promoção do equilíbrio nessa relação, mas não é que temos encontrado hodiernamente. Neste ínterim, a Lei $n^{\circ}$ 13.874/2019 (Lei de Liberdade Econômica), fruto da MP no 881 de 30 de abril de 2019, surge neste contexto histórico de fragilização dos direitos trabalhistas iniciada com a Lei $\mathrm{n}^{\circ}$ 13.467/2017 (Reforma Trabalhista), no escopo de atender a agenda neoliberal.

Assim, em volvo das aclaradas contradições ideológicas hegemônica que prega o predomínio de uma hipotética liberdade para empreender sobre direitos laborais como um todo, o presente trabalho científico tem como escopo principal analisar as alterações legislativas relativas ao Controle de Jornada de Trabalho emanadas da Lei $\mathrm{n}^{\circ}$ 13.874, de 20 de setembro de 2019 (Lei de Liberdade Econômica) à luz dos Princípios Protetivos do Trabalhador.

Assim sendo, o presente artigo será dividido em 4 (Quatro) tópicos. No primeiro tópico haverá uma contextualização acerca do Controle de Jornada no Direito do Trabalho e a sua importância na Saúde e Segurança do Trabalho, ocasião em que será apresentado como fundamento tripartite para o controle de duração do trabalho os aspectos biológico, social e econômico, consoante defende a Professora Vólia Bomfim Cassar (2018).

Enquanto que no segundo tópico será exposto os motivos que levaram a criação da Lei de Liberdade Econômica (Lei $\mathrm{n}^{\mathrm{o}}$ 13.874/2019), a qual teve como principal bandeira do seguimento neoliberal a desburocratização e promessa de uma suposta segurança jurídica e fomenta dos postos de emprego. 
Outrossim, no terceiro tópico será apresentado o Princípio da Proteção e a sua subdivisão formada pelo tripé principiológico, a saber: i) o Princípio do in dubio pro operário; ii) o Princípio da Utilização da Norma mais favorável; e o iii) Princípio da Aplicação da condição mais benéfica. Enquanto no quarto tópico iremos verificar as alterações legislativas e impactos promovidos pela Lei n ${ }^{\circ}$ 13.874/2019 (Lei de Liberdade Econômica) no Controle de Jornada de Trabalho à luz da principiologia protetiva.

Para tanto, este trabalho parte de um estudo documental, no qual as fontes são esparsas, diversificadas e pendentes de um tratamento analítico, bem como uma averiguação bibliográfica, haja vista, neste último, a utilização fundamentalmente dos aportes dos diversos estudiosos sobre determinado assunto. Nesta senda, corrobora Antônio Carlos Gil (2002, p. 45): "A pesquisa documental assemelha-se muito à pesquisa bibliográfica. A diferença essencial entre ambas está na natureza das fontes".

No intento de alcançar o desiderato científico proposto, utilizar-se-á de abordagem qualitativa, bem como da revisão de literatura e método dialético, com fulcro em alguns renomados juristas especialistas em Direito do Trabalho, à exemplo de: Vólia Bomfim (2018), José Cairo Jr. (2021) e Amauri Mascaro Nascimento (2013).

Ademais, é evidente que a temática ganha espaço por dispor sobre um assunto atual e relevante, seja pelo atual contexto de fragilização das regras trabalhistas, seja pela inquestionável relevância do Controle da Jornada de Trabalho para a Saúde e Segurança do Trabalho. Logo, mister fomentar o debate sobre a temática em estudo e sobre os direitos dos trabalhadores.

1. Do controle de Jornada no Direito do Trabalho e a sua relevância na Saúde e Segurança do Trabalho.

A temática Jornada (Duração do Trabalho) - em concomitância com o tema Salário/Remuneração - tem destaque na evolução do Direito Laboral, ocupando posição central nos diferentes debates e embates, os quais contribuíram para a consagração daquele enquanto ramo autônomo do Direito.

Neste ínterim, importante anotar que fundamento da Jornada e, respectivamente, o seu Controle encontram guarida nas regras de Medicina e Segurança do Trabalho, conforme nos ensina a Professora Vólia Bomfim Cassar (2018). Assim, torna-se possível dizer que o amparo 
para o controle da duração do trabalho diário apresenta 3 (três) pontos de vista, quais sejam: biológico, social e econômico.

Isto porque, convém esclarecer que o trabalho em excesso pode provocar estresse, aumento de peso, inviabiliza o convívio com familiares e amigos; como também, contribui para a baixa produtividade do colaborador e, portanto, apequenando possíveis vantagens econômicas para o patrão. Portanto, os 03 (três) fatores retromencionados são imprescindíveis para limitar o número de horas diárias de labor prestado pelo obreiro à empresa.

Nesta esteira de pensamento, Sérgio Pinto Martins (2001, p. 437) conceitua Jornada como sendo “(...) diz respeito ao número de horas diárias de trabalho que o trabalhador presta à empresa.".

Nesta linha de intelecção, a Professora Vólia Bomfim Cassar (2018, pág. 610) diz:

Este é o conceito mais técnico do instituto, uma vez que na linguagem forense é comum a utilização da expressão jornada no sentido mais amplo, isto é, abrangendo lapso temporal de maior duração. [...] A jurisprudência e os operadores trabalhistas frequentemente utilizam a expressão 'jornada de 8 horas diárias', sem perceber a redundância cometida, pois jornada quer dizer horas trabalhadas em um dia e diária também significa dia.

Já o doutrinador Amauri Mascaro Nascimento (2013) defini a jornada de trabalho como sendo o tempo à disposição de empregador, ainda que não esteja trabalhando efetivamente. $\mathrm{Na}$ mesma vertente, preceitua a Consolidação das Leis do Trabalho (CLT), materializada em seu Artigo $4^{\circ}$ e seguinte, a dizer:

Considera-se como de serviço efetivo o período em que o empregado esteja à disposição do empregador, aguardando ou executando ordens, salvo disposição especial expressamente consignada.

O saudoso Mestre Arnaldo Süssekind (2000, p. 808) leciona que o horário de labor “[...] é a fixação dos momentos em que deve ter início e fim a jornada normal de trabalho e, se for o caso, do intervalo para descanso ou refeição [...]". Ao passo que o legislador justrabalhista entendeu por considerar o tempo que empregado fica à disposição do empregador aguardando deliberação por parte deste, como tempo de serviço prestado. Tal ficção legal teve o intento de proteger os colaboradores dos abusos do poder econômico, por ventura cometidos pelo patrão, a exemplo de: tempo à disposição decorrente da restrição do direito de ir e vir, intervalos não estabelecidos pela legislação, tempo de espera de serviço quando em trabalho, sobreaviso, prontidão etc. 
Assim sendo, no escopo de alcançar a sua finalidade protetiva, até o dia 19 de setembro de 2020, o Art. 74, parágrafo $2^{\circ}$, CLT, prelecionava:

Para os estabelecimentos de mais de dez trabalhadores será obrigatória a anotação da hora de entrada e de saída, em registro manual, mecânico ou eletrônico, conforme instruções a serem expedidas pelo Ministério do Trabalho $^{3}$ devendo haver pré-assinalação do período de repouso.

Tal exigência não se apresenta apenas como uma justificativa que leva à importância do Controle do Jornada de Trabalho. Vale esclarecer que o registro do número de horas trabalhadas diariamente permite que o empregador possa conferir os rendimentos de seus colaboradores. Neste sentido, a verificação pode ser feita manualmente, de forma mecânica ou digital, disponibilizando uma métrica das horas trabalhadas, de atrasos, das horas extras e afins.

Portanto, percebe-se que de um lado temos a avaliação de produtividade do obreiro e do outro a segurança ao trabalhador de que as suas horas laboradas serão adimplidas corretamente, conforme previsto no Art. $7^{\circ}$, XIII, da Carta da República de 1988. Assim, a prova do tempo efetivamente laborado permite quantificar a hora de trabalho e, com efeito, o dever de pagar pelo período extraordinário com acréscimo dos adicionais legais e convencionais.

Para tanto, o controle de horário pode ser feito de forma manual (Livro de Ponto), mecânica (Relógio de Ponto) ou, ainda, eletrônica (Cartões Magnéticos, Controle Biométrico etc), conforme instruções expedidas pela atual Secretaria do Trabalho, vinculada ao Ministério da Economia.

Ademais, considerando que as mudanças na ciência jurídica é um fenômeno corriqueiro e intimamente relacionada com as tomadas de decisões nas esferas governamentais, cumpre dizer que a partir do final do primeiro semestre de 2016 nota-se uma modificação no perfil neodesenvolvimentista da política brasil até então adotada desde 2003 (Souza; Hoff, 2019 apud Boito \& Berringer, 2013). Com tal rompimento, passa-se a verificar domadas de decisões de cunho liberalizantes, a exemplo da Lei no 13.874/2019 (Lei de Liberdade Econômica), com a atual gestão do Governo Federal.

\section{A Lei de Liberdade Econômica (Lei no 13.874/219)}

\footnotetext{
${ }^{3}$ Atual Secretaria do Trabalho do Ministério da Economia.
} 
No escopo de atenuar a burocracia, fomentar a criação e formalização de novas empresas e criar uma nova dinâmica ao setor empresarial - anseio do empresariado -, o Poder Executivo sancionou a Lei no 13.874/2019, também conhecida como Lei de Liberdade Econômica.

Neste compasso, mister relembrar que a testilha aos "entraves burocráticos" fora uma das bandeiras de campanha da atual Gestão Executiva Federal, uma vez que se tratava de uma temática objeto de inúmeras reclamações do Setor Patronal. Mas, o que de fato é a Lei de Liberdade Econômica? Quais foram as principais alterações e como ela afeta as normas trabalhistas (CLT)?

A Lei $n^{\circ}$ 13.874/2019 (Lei de Liberdade Econômica) prescreve normas destinadas a salvaguardar a livre iniciativa das atividades produtivas e abrandar a participação do Estado como agente de intermediação e regularização. Nesta linha de intelecção, Mariana Almeida Santos e Tuila Rafaela Vieira Torres (2019, p. 244) asseveram:

[...] a aprovação pelo Senado do texto final para conversão em lei da Medida Provisória $n^{\circ} 881 / 2019$, conhecida como MP da Liberdade Econômica, que propõe medidas de desburocratização e simplificação de processos para empresas e empreendedores.

Quanto às suas medidas, estas são bastante amplas e se aplica a diversos setores, caminhando pelo Direito Civil (Registro Público), Urbanístico (Transporte), Empresarial (Junta Comercial), Econômico (Comércio), entre outro. No âmbito da relação juslaborativa, em destaque no tocante à jornada de trabalho, anota-se que o pequeno e médio empreendedor, certamente, fora o maior beneficiário. Isso porque foi flexibilizado a imposição do registro obrigatório da jornada de trabalho que afeta as empresas que detinham mais de 10 (dez) empregados. A partir de então, a obrigatoriedade do registro da jornada de trabalho dos seus colaboradores fica restrito às empresas que contam com mais de 20 (vinte) colaboradores. Nesta linha de intelecção, Ana Beatriz Bueno de Jesus, Bruna da Penha de Mendonça Coelho e Giulia Valente de Lacerda Cunha (2019, p. 08) asseveram:

Já em relação ao quadro discriminativo de horários de empregados, este já não mais será necessário nos termos da lei, sendo que a pré-anotação dos períodos de repouso tornou-se mera faculdade. Haverá obrigatoriedade do controle de horário, para os estabelecimentos com mais de 20 trabalhadores (antes era para estabelecimentos com mais de 10 trabalhadores), conforme a alteração no artigo $74, \S 2^{\circ}$, CLT, permitida a pré-assinalação do período de repouso (intervalo intrajornada). 
Outrossim, ainda no tocante à jornada, registra-se que Lei de Liberdade Econômica trouxe ao debate jurídico uma questão outrora discutida e que na prática era vedada há anos: a marcação do ponto por exceção.

À guisa de conhecimento, imprescindível anotar que o precedente jurídico acerca do ponto “por exceção” ficara limitada na decisão da Quarta Turma do Superior Tribunal do Trabalho - TST, quando entendeu por ser válido desde que haja previsão em norma coletiva (RR-1001704-59.2016.5.02.0076). A partir de 2019, com a alteração do $\S 4^{\text {o }}$, do Art. 74, da CLT, o legislador permitiu a pactuação do registro do ponto "por exceção" através de acordo individual ou norma coletiva, acompanhando o entendimento da $4^{\mathrm{a}}$ Turma do TST.

E como opera o controle de ponto de forma excepcional? A sua própria denominação já nos permite pensar tal modalidade pressupõe de que o horário firmado em contrato de trabalho é sempre respeitado. E, desta forma, tal modalidade excepcional de registro de ponto consiste em uma prática pela qual os empregados somente registrarão o ponto em situação extraordinárias, ou seja, se presumirá uma jornada ordinária e, tão somente, as ausências, atrasos, horas extras realizadas, entre outras situações exceptuais necessitarão ser anotadas no Controle de Jornada.

Destarte, enxerga-se que algumas medidas contidas na Lei de Liberdade Econômica (Lei $\mathrm{n}^{\mathrm{o}}$ 13.874, de 20 de setembro de 2019) foram bem promissoras no que se refere a desburocratização, todavia, é de alertar que, como toda alteração, traz consigo a necessidade do (re) pensar e, com efeito, implementar novos métodos no escopo de adequação. Nesta toada, pode mencionar o exemplo do Controle de Registro de Ponto, que, acima do debate quanto a sua obrigatoriedade, traz benefícios alhures listados para os protagonistas da relação laboral (Empregado e Empregador), os quais, por vezes, encontram respaldo nas bases principiológicas juslaboral.

\section{Princípios Protecionistas do Direito do Trabalho}

Notório que a ontologia juslaboral é essencialmente protecionista e após a constatação de que seus ideários jurídicos trabalhistas sustentam o ordenamento legal, torna-se importante conhecer os Princípios protetivos e suas principais manifestações no Direito do Trabalho.

Não diferente dos outros ramos da Ciência Jurídica, o Direito do Trabalho possui alguns Princípios que o norteiam, quais sejam: o Princípio da Proteção, o Princípio da Irrenunciabilidade de Direitos, o Princípio da Continuidade da Relação de Emprego, o Princípio 
da Primazia da Realidade, o Princípio da Inalterabilidade Contratual Lesiva e o Princípio da intangibilidade Salarial. Todavia, aprofundaremos nosso estudo acerca deste primeiro, o Princípio da Proteção.

O de maior amplitude e relevância para o Direito do Trabalho, o Princípio da Proteção atribui ao empregado uma superioridade jurídica, uma vez límpida a condição de fraqueza deste na relação de trabalho. Tal vantagem asseguram mecanismos destinados a proteger direitos mínimo prescritos na legislação. Para tanto, o Princípio da Proteção se subdivide em 03 (três) outros Princípios, a saber: i) o Princípio do in dubio pro operário; ii) o Princípio da Utilização da Norma mais favorável; e o iii) Princípio da Aplicação da condição mais benéfica.

Neste ínterim, o Princípio do in dubio pro operário no ensina que na dúvida entre duas ou mais interpretações, deve-se optar pela mais vantajosa ao colaborador. Nesta mesma linha de intelecção, Alfredo Ruprecht (1995, p. 15) diz que “(...) significa que uma mesma norma, quando susceptível de diversas interpretações, deve ser aplicada a que mais beneficia ao trabalhador.".

A referida lógica jurídica se justifica uma vez que, nas relações de trabalho, a desvantagem encontra-se, inversamente às diretrizes gerais do Direito Privado, no Polo Ativo. Isto porque, é o obreiro que apresenta a condição de hipossuficiência, encontrando na remuneração (na maioria das vezes, apenada) a sua condição de sobrevivência. No tocante a retromencionada alteração do regramento fático, o Professor Luiz de Pinho Pedreira da Silva (1999, p. 30) explica a inversão em relação aos Princípios In dubio pro reo (Relação Cível) ou In dubio pro devedor (Relação Comercial), senão vejamos:

Se o Direito Privado aceita o princípio do favor pro reo é porque, na generalidade das relações civis ou comerciais, o devedor é mais débil e necessitado. Mas nas relações de trabalho ocorre exatamente o contrário, porquanto a generalidade dos casos o trabalhador, cuja situação em face do empregador constitui pressuposto básico do Direito do Trabalho, se apresenta como credor diante de seu empregador (devedor).

Por outra via, salienta-se que tal preceito interpretativo não é absoluto, sendo que tal regra se aplica de modo sobejo na hipótese de interpretação das de regras juslaborais heterônomas e autônomas, como também, anota-se que a sua condição de aplicabilidade ocorre quando se opera a ambiguidade da norma objeto de interpretação. Enquanto que Renato Saraiva, Rafael Tonassi e Aryanna Linhares (2019, p. 17) lecionam que: 
(...) não se aplica o Princípio do in dubio pro operário, pois o direito processual (arts. 818, CLT e 373, CPC) impõe ao autor a prova do fato constitutivo do direito e ao réu, a prova do fato modificativo, extintivo ou impeditivo do direito.

Ato contínuo, cumpre avançar dentro a perspectiva protecionista em um outro Princípio coirmão, que o Princípio da norma mais favorável, modernamente denominada "aplicação da norma estatal mais favorável” (CAIRO, 2021, p. 106). Tal Princípio apresente é de suma relevância para a salvaguardo do hipossuficiente, uma vez que a adoção da prevalência da norma superior hierárquica iria em contramão ao Princípio da Proteção e ao escopo basilar do Direito do Trabalho.

Contribuindo com seus ensinamentos fulcrais, o Professor Pinho Pedreira (1999, p. 65) leciona:

O princípio da norma mais favorável é mais amplo, em termos de proteção, e o único incontestavelmente específico do Direito do Trabalho, pois nenhuma outra disciplina jurídica e em nenhum caso, ao menos no Brasil, admite-se a aplicação de norma hierarquicamente inferior com desprezo da hierarquicamente superior.

Como se vê, a norma principiológica se destaca tanto pela finalidade basal de ratificar a proteção conferida, quanto se diferenciar frente aos métodos habituais de interpretação.

Assim, considerando o contexto plural de fontes no Direito do Trabalho, o Princípio da norma mais favorável consiste na aplicação do regramento mais benéfico ao obreiro, independentemente de seu arranjo hierárquico (SARAIVA, TONASSI \& LINHARES, 2019). Ao passo que o Eminente Ministro do Tribunal Superior do Trabalho Maurício Godinho Delgado (2004, p. 85) delineia como:

(...) no processo de aplicação e interpretação do Direito, o operador jurídico situado perante um quadro de conflito de regras ou de interpretações consistentes a seu respeito deverá escolher aquela mais favorável ao trabalhador, a que melhor realize o sentido teleológico essencial do Direito do Trabalho.

Nesta linha de pensamento, a Corte Superior Trabalhista vem adotando o Princípio em questão, especialmente, quando se busca afiançar os itens e dispositivos mais vantajosos prefixados em normas coletivas. Um outro exemplo do Princípio da norma mais benéfica é o caso da coexistência de gratificação por tempo de serviço outorgado pelo empregador e outra da mesma natureza prevista em regramento coletivo ou sentença normativa, de modo que o empregado tem direito a receber, exclusivamente, a que lhe seja mais benéfica, conforme magistério da Súmula $\mathrm{n}^{\circ} 202$ do TST. 
Ademais, a terceira "proposição nuclear" (HOUAISS, 2001, p. 2299) que compõe a tríade do Princípio da Proteção, é o Princípio da condição mais beneficia. Tal Princípio determina que as circunstâncias apresentadas como vantajosas e estipuladas no contrato de trabalho do empregado ou preestabelecida no regulamento da empregadora deverão prevalecer, independentemente, de norma superveniente que verso sobre matéria específica, instituindo condição diversa e apenando o nível proteção ao obreiro. Assim sendo, ressaltam Renato Saraiva, Rafael Tonassi e Aryanna Linhares (2019) que o regramento jurídico superveniente, tão somente, produzirá efeitos para os novos contratos de trabalho.

Corroborando, o uruguaio Américo Plá Rodriguez (2000, p. 131) ensina que:

A regra da condição mais benéfica, pressupõe a existência de uma situação concreta, anteriormente reconhecida, e determina que Lei deve ser respeitada, na medida em que seja mais favorável ao trabalhador que nova norma aplicável.

Quanto a sua materialização no plano constitucional, cumpre mencionar que o Princípio da condição mais benéfica encontra fundamento nos Artigos $5^{\circ}$, Inc. XXXVI, e $7^{\circ}$, Caput, da CF de 1988; bem como, amparo no Direito Adquirido. Já na espera do direito infraconstitucional trabalhista, registra-se que a sua consagração no Artigo 468 da CLT, com o impeditivo para alterações contratuais lesivas.

Ademais, compete refletir tanto este último princípio como os demais alhures mencionados vêm sendo relativizados, quiçá contestados, conforme já defendeu o Pesquisador Murilo Carvalho Sampaio Oliveira (2006) em sua brilhante dissertação pela Universidade Federal da Bahia-UFBA.

\section{A Lei $\mathbf{n}^{0}$ 13.874, de 2 de setembro de 219 (Lei de Liberdade Econômica) e o Controle de Jornada à luz dos Princípios Protetivos do Trabalhador}

Em primeiro plano, como já destacado, a vigência da Lei no 13.874/2019 modificou diversos dispositivos da Consolidação das Leis do Trabalho (CLT), em relevo o Artigo 74, Parágrafos $2^{\circ}$ e $3^{\circ}$ e acréscimo do Parágrafo $4^{\circ}$. Ao considerar a relevância do tema alterado, a análise acerca da flexibilização das normas trabalhistas à luz de sua principiologia norteadora se sobressai, uma vez que esta, conforme ensina o dileto Prof. José Cairo Jr. (2021, p. 103):

(...) orienta o operador do Direito na sua atividade interpretativa, além de ser classificado como meio de integração das eventuais lacunas legais. Serve, também, para guiar o legislador quando no exercício da sua função de 
legiferar, fato que leva o princípio a ser um elemento presente em todo o sistema jurídico do qual fez parte.

Nesse panorama, salutar destacar que o presente trabalho não intenta descreditar o Princípio da Livre Iniciativa, o qual apresenta papel de extrema importância para o Direito Empresarial. Igualmente, assinala que este trabalho não objetiva discutir a inconstitucionalidade formal da retromencionada legislação, a qual já fora muito bem defendida pelas Acadêmicas da Universidade Federal do Rio de Janeiro (UFRJ), Ana Beatriz Bueno de Jesus, Bruna da Penha de Mendonça Coelho e Giulia Valente de Lacerda Cunha (2019).

Por outra via, não é de difícil percepção que a Lei de Liberdade Econômica supervalorizou o Princípio da Livre Iniciativa em detrimento de Princípios com o da Valorização do Trabalho Humano, do Valor Social do Trabalho e, em destaque, o da Proteção, sem haver uma ponderação, conforme leciona o Professor Marcelo Leonardo Tavares (2003). Nesta senda, não é difícil de imaginar os efeitos jurídicos, como a consequente aplicação demasiada da liberdade de iniciativa nas decisões jurídicas, afastando, em nosso entender, de sua característica central de proteger o empregado, que é considerado hipossuficiente, com escopo de alcançar o seu desiderato fulcral de fomentar melhores condições de trabalho e a harmonia social, seja por meio da intervenção estatal, seja por meio das negociações coletivas.

Outro aspecto da lei é em relação à temática Jornada de Trabalho. Com o advento da Lei intitulada de Liberdade Economia e a alteração do Art. 74 da CLT, percebe-se uma inversão do ônus da prova em favor do empregador com até 20 (vinte) empregados, em sentido oposto ao Ensinamento Sumular $n^{\circ} 338$ do TST. Não fosse o suficiente, a modificação legislativa em debate desguarnece a maior parte da massa celetista no Brasil, porquanto, no ano de 2020, aponta o Serviço Brasileiro de Apoio às Micro e Pequenas Empresas (SEBRAE), os micro e pequenos negócios representam 99\% (Noventa e nove por cento) do total das empresas no território nacional, sendo que as pequenas companhias são as que mais geram empregos formais, alcançando um percentual de $54 \%$ (Cinquenta e quatro por cento), tendo no comércio a maior concentração das empresas, somando $41 \%$ (Quarenta e um por cento). ${ }^{4}$ Ressalta-se, ainda, que a maior parte da empreendimentos comerciais não possuem mais de 20 (Vinte)

\footnotetext{
${ }^{4}$ SEBRAE - Serviço Brasileiro de Apoio às Micro e Pequenas Empresas - Portal do Desenvolvimento Local. Site disponível: < https://portaldodesenvolvimento.sebrae.com.br/sebrae-aponta-que-pequenas-empresas-geram-maisempregos-no-

brasil/\#: :text=As\%20pequenas\%20companhias\%20s\%C3\%A3o\%20as,servi\%C3\%A7os\%20que\%20mais\%20e mprega\%20mulheres.>. Acesso em 28 de maio de 2021.
} 
colaboradores. Enfim, resta límpido a modificação do Art. 74 da CLT desfavorece a maioria dos trabalhadores brasileiros e surge em contramão ao Princípio da Proteção, de maior relevância na seara juslaboral.

Não só, a Lei no 13.874/2019 ao inovar com inclusão do Parágrafo $4^{\circ}$ ao Art. 74, da CLT, permitiu a hipótese do ponto por exceção como alternativa ao registro do ponto mais habitual, em razão de sua simplicidade. O objetivo por trás desta modalidade de controle é que o trabalhador fará o registro de ponto de modo extraordinária e poderá ser firmado mediante acordo individual escrito, convecção coletiva ou acordo coletivo de trabalho.

De passo a passo, frisa-se que ao facultar a utilização do ponto por exceção mediante acordo individual escrito, o legislador deixa de promover meios de atenuar a desigualdade existente na relação empregado-empregador. Ao contrário, no atual contexto é de convir que o colaborar tende a se sujeitar às vontades do empregador, sob o risco de ter o seu contrato resilido. Assim sendo, o colaborador é sujeitado ao ciclo vicioso de patente servidão.

Além do mais, não podemos deixar de consignar que reputada a importância prestígio do controle de jornada de trabalho para a Segurança e Medicina do Trabalho, bem como a adjacente relação desta com o Princípio da Proteção, não resta dúvida que a flexibilização nega o Princípio da Proteção.

Dessarte, não obstante a Lei de Liberdade Econômica tenha sido anunciada como mecanismo para estimular a economia a partir da desburocratização, entretanto, o que se viu no trimestre seguinte do início da retromencionada legislação foi o aumento da informalidade que atinge 41,1\%, conforme Pesquisa de Amostras por Domicílios (PNAD) Contínua divulgada em 31 de janeiro de 2020. Logo, resta evidente que o retromencionado dispositivo não atingiu o seu desiderato, como também supervalorizou o Princípio da Livre Iniciativa em prejuízo de princípios fundamentais para o Direito do Trabalho como os Princípios do Valor Social do Trabalho, da Valorização do Trabalho Humano e, principalmente, da Proteção.

\section{CONCLUSÃO}

Diante do exposto, resta evidente que este artigo fomentou uma reflexão quanto ao Controle de Jornada no Direito do Trabalho e sua relevância para a Saúde e Segurança do Trabalhador, em especial, quando se verifica o seu carácter multifacetado; como também, fica demonstrado que a escopo principal da Lei de Liberdade Econômica (Lei n ${ }^{\circ} 13.874 / 2019$ ) não 
atingiu o seu desiderato e que apresenta elementos justificadores de sua inconstitucionalidade material quando analisado à luz dos Princípios Protetivos do Trabalhador.

Neste liame, há de se levar a consciência o papel do Controle de Jornada para todos os agentes envolvidos na relação de trabalho, em destaque, para empregados, hipossuficientes nesta relação. A exposição da importância do Registro do Controle de Jornada tomou como base os enfoques biológica, social e econômica a partir dos ensinamentos da Professora Vólia Bomfim Cassar (2018). Igualmente, se consigna que fixação deste regramento legal visa proteger os obreiros dos abusos de Poder Econômico, que por ventura venha a ser cometido por empregadores.

À vista disso, acredita e reitera a necessidade de promoção de debates e reflexões neste cerne, a fim de se assegurar garantias mínimas àqueles que compõem a força de trabalho, de modo a afiançar as condições adequadas de labor e evitar violações ao regramento legal quanto à jornada de trabalho, a qual refletirá na saúde do trabalhador.

Por outro lado, a Lei nº 13.874/2019 (Lei de Liberdade Econômica) sob estudo, pungiram discussões ainda mais calorosas, uma vez que esta supervalorizou princípios como o da Livre Iniciativa, sob o suposto argumento de aceleração da economia. Entretanto, consoante dados trazidos neste artigo demonstram tal crescimento econômico não ocorrera como esperado e o que se visualizou foi uma maior fragilização dos Direitos Trabalhistas, com alheamento aos Princípios da Valorização do Trabalho Humano, do Valor Social do Trabalho e, especialmente, o da Proteção.

Assim sendo, imprescindível suscitar que o conflito entre Capital e Trabalho assalariado forma a lógica da relação laborativa, de modo que a contentamento de um lado não representará a satisfação do outro, conforme defende o Professor Manuel Carlos Palomeque Lopez (2011). Em um verdadeiro jogo de "soma zero".

Diante do exposto, torna-se irrefragável a pertinência mais do que nunca de mecanismo que buscam atenuar a desigualdade existente na relação empregado-empregador, pautada sempre na ponderação ensinada pelo ilustre Professor Marcelo Leonardo Tavares (2003), assegurando os ideários principiológicos desta seara especializada e nunca esquecendo que o Direito do Trabalho é política social! 


\section{REFERÊNCIAS}

CASSAR, Vólia Bomfim. Direito do trabalho: de acordo com a reforma trabalhista. 16. ed. ver. e atual. Rio de Janeiro: Forense, São Paulo: Método, 2018.

DELGADO, Maurício Godinho. Princípios de direito individual e coletivo do trabalho. $2^{\mathrm{a}}$ Ed. São Paulo: LTr, 2004.

GIL, Antônio Carlos. Como elaborar projetos de pesquisa. 4. ed. São Paulo: Atlas, 2002. JESUS, Ana Beatriz Bueno de; COELHO, Bruna da Penha de Mendonça; CUNHA, Giulia Valente de Lacerda. A minirreforma trabalhista: Uma reflexão crítica de seus possíveis impactos sociais. Revista Eletrônica OAB/RJ, Rio de Janeiro, V. 30, N. 2, p. 01-16, jul/dez, 2019.

NASCIMENTO, Amauri Mascaro. Curso de direito do trabalho: história e teoria geral do direito do trabalho: relações individuais e coletivas do trabalho. $28^{a}$ edição. São Paulo: Saraiva, 2013.

OLIVEIRA, Murilo Carvalho Sampaio. (Re) pensando o princípio da proteção na contemporaneidade. Dissertação (Mestrado em Direito) - Faculdade de Direito, Universidade Federal da Bahia. Salvador. p. 239. 2006.

PINTO, Sérgio. Direito do Trabalho. 13. ed. São Paulo: Atlas, 2001.

PLÁ RODRIGUEZ, Américo. Princípios do Direito do Trabalho. $3^{\mathrm{a}}$ edição, São Paulo: Ltr, 2000;

RUPRECHT, Alfredo J. Os princípios de direito do trabalho. Tradução Edílson Alkmim Cunhal. São Paulo: LTr, 1995.

SANTOS, Mariana Almeida; TORRES, T. R. V. Impactos da medida provisória de liberdade econômica no âmbito do Direito do Trabalho. In: Anais do XIV EVINCI Evento de Iniciação Científica, v. 5, n. 1, p. 244-244, 2019, Curitiba-PR.

SILVA, Luiz Pinho Pedreira de. Principiologia do Direito do Trabalho. São Paulo: LTr, 1999. 
SOUZA, M. B.; HOFF, T. S. R. Governo Temer e a volta do neoliberalismo no Brasil: possíveis consequências para a habitação popular. urbe. Revista Brasileira de Gestão Urbana, 11, 2019, e20180023.

SÜSSEKIND, Arnaldo; MARANHÃO, Délio; VIANNA, Segadas; TEIXEIRA, Lima.

Instituições de direito do trabalho. 19. ed. São Paulo: LTr, 2020, v. II.

TAVARES, Marcelo Leonardo. Previdência e Assistência social: Legitimação e

Fundamentação Constitucional Brasileira. Rio de Janeiro: Lumem Juris, 2003. 